\title{
An Analytical Study to Assess the Awareness Level of Para-veterinarians about Antibiotic Resistance in Eastern Haryana, India
}

\author{
Vikash Kumar* and Jancy Gupta \\ Division of Dairy Extension, ICAR-NDRI, Karnal-132001, Haryana, India \\ *Corresponding author
}

\begin{tabular}{l} 
Ke y w or d s \\
Health crisis, \\
Incompetency, \\
Diagnostic \\
practices, Outreach, \\
Decision-making. \\
Article Info \\
\hline $\begin{array}{l}\text { Accepted: } \\
17 \text { September } 2017 \\
\text { Available Online: } \\
10 \text { October } 2017\end{array}$ \\
\hline
\end{tabular}

A B S T R A C T

The issue of antibiotic resistance has become a catastrophe of the scenario witnessed by increasing animal's health crisis and burden of infectious diseases in India. It demands judicious extension approaches and outreach to track the decision-making among the stakeholders. The behaviour of Para-veterinarians (Paravets) regarding the antibiotic prescription and use were focussed in the study. The awareness of paravets regarding antibiotic resistance was measured using an Index developed for this study. The study revealed that paravets were having general awareness about antibiotic resistance but were not aware that it had spread throughout the geographical area. The antibiotic prescribing behaviour of paravets was also studied in detail. It was found that paravets were lacking appropriate knowledge about diagnostic practices and consequences. Low level of awareness about antibiotic resistance was found among 44 percent of paravets. They were unable follow judicious prescription of antibiotics due to lack of awareness and technical incompetency.

\section{Introduction}

Paravets provide advice and access to medicines to treat sick animals; they live in the villages and have close proximity with farmers. They receive training in administering injections, drenching, treating wounds and hoof trimming which help them to gain confidence in services, paving way for veterinary consultancy for dairy farmers. Thus, they treat animals at low cost based on their experience and prescribe antibiotics to treat bacterial diseases leading often to its over-use. They also receive training in administering injections, drenching, treating wounds and hoof trimming which helped them to gain confidence in services provided paving a way for veterinary consultancy for dairy farmers. Although, paravets were provided initial training to assist veterinarians but they are not authorised to practice prescription of antibiotics. They were preferred mostly by the smallholder dairy farmers because of low consultation and services fee as compared with veterinarians. Although veterinarians should the main source of information, veterinary consultancy and services but limited finances for expenditure on veterinary support for dairy farmers was a key barrier in seeking out antibiotic protocols (Friedman et al., 2007). The choice of appropriate antimicrobials for 
treatments may also be affected by farmers' own opinions and perceived needs i.e. withdrawal period, cost and profit margin, ease of medicine administration (De Briyne et al., 2013). Thus, farmer's choice for veterinary consultancy is directly affects antibiotic prescription, prescription behaviours and antibiotic resistance. The over-use of antibiotics in livestock production is considered as major factor for increasing the antibiotic resistance in humans (Schwarz et al., 2001). The In the year 2013, the G8 summit identified antimicrobial resistance as the major health security challenge of the $21^{\text {st }}$ century (Gulland, 2013). It calls for the investigation about cross-resistance and coselection mechanisms which resulted transfer of resistance along the food-chain. Our understanding regarding the effect of subinhibitory levels of antibiotics in environment resulted the selection of bacteria and resis to some burden aggravated the antibiotic contamination due to horizontal gene transfer is limited (Berglund, 2015). It calls for the investigation about cross-resistance and coselection mechanisms which resulted transfer of resistance along the food-chain. The G7 summit in 2015 stressed the One Health Approach which integrated the antibiotic usage among human and livestock from the common point of view by considering the interlinked transfer of resistance among both the species (Harbarth et al., 2015).

\section{Materials and Methods}

The study was conducted in the Eastern Haryana zone in which two districts namely Karnal and Kurukshetra were purposively and from each district twelve paravets were selected randomly for assessing the awareness about antibiotic resistance because they were performing the veterinary aid and artificial insemination and other services to dairy farmers in the study area. An awareness Index was developed to assess the awareness level of paravets about antibiotic resistance. The following steps were considered for construction of Awareness Index.

\section{Selection of indicators}

The multidimensional aspects include general awareness about antibiotic resistance, farmer's behavioural aspects, animal husbandry practices at farm level, environmental impact, spread and contamination by antibiotic resistance etc. issues. Therefore, selected indicators were representative of the field with the help of review of literature.

\section{Determination of scale values}

Normalized Rank Order Method suggested by Guilford (1954) was used to assign scale values. As per the method, five different indicator of Awareness Index were ranked by the group of judges as per perceived significance. Ranking was obtained from judges who involved 40 experts in the field of Social Science, ICAR-NBAGR, Karnal and Dairy Microbiology Division, NDRI. Out of 40 judges 35 judges had returned the same set of indicators after duly recording their judgments in a stipulated span of 2 months. Out of 35 responses, 5 responses were found unsuitable thus were eliminated. The remaining 30 responses were considered for the item analysis. The proportions were worked out for the ranks assigned by all the judges using the following formulae:

$$
\mathrm{p}=\text { - } \mathrm{( \textrm {Ri } - 0 . 5 ) ^ { * } 1 0 0}
$$

Where $\mathrm{Ri}$ stands for the rank value of the dimension $\mathrm{i}$ in the reverse order as 5 to 1 and $\mathrm{n}$ indicates the number of indicator ranked by the judges. The $p$ is the centile value which indicated the area of the indicator in the normal distribution. The $\mathrm{C}$ values were 
determined for each rank from the Table-M (Guilford 1954, p. 577 In the case of this experiment the numbers of Indicator were 5, which were ranked. The $\mathrm{C}$ values are ranging from 1 to 9 only.

The same procedure may be adapted in finding out the $\mathrm{C}$ values for all the ranks ( $r i$ ) from the Table-M. The next step $\Sigma f \mathrm{C}$ value for each indicator was obtained by multiplying the frequencies found in the columns of the respective dimension by the $\mathrm{C}$ values of the rank (ri), followed by summing up the products for each indicator and entering the same in the row against $\sum \mathrm{f} \mathrm{C}$. Thereafter, the $\sum \mathrm{f} C$ values for each dimension was divided by the total number of judges 30 for obtaining the Mc (mean value) or $\mathrm{Rj}$ (response value) for each dimension. The Frequencies of Ranks as given by 30 Judges, Proportions (p), C Values and Rc Values for five Indicators of Awareness Index by using Normalized Rank Order Method Suggested by Guilford (1954).

\section{Collection and editing of statements}

By referring the available literature, a total 70 statements which were edited as per 74 informal criteria suggested by Edwards (1957) out of which, 35 statements were eliminated and35 statements were retained after editing for judge's rating.

\section{Response to statements}

The Performa was sent by post, through email and also handed over personally to the total 40 judges who were experts from NDRI and NBAGR, Karnal (Table 2).

\section{Relevancy test}

Three point continuums as 'Most Relevant, Relevant and Least Relevant' with scoring 3, 2 , and 1 were used. The Relevancy Weightage
(RW) and Mean Relevancy Score (MRS) were worked out for all the selected statements individually by using the following formula

$$
\text { fxi } * 3+\text { fxii }^{*} 2+\text { fxiii } * 1
$$

Relevancy Weightage $(\mathrm{RW})=$

$$
\mathrm{fx} * 3
$$

$$
\mathrm{fx}_{\mathrm{i}} * 3+\mathrm{fx}_{\mathrm{ii}} * 2+\mathrm{fx}_{\mathrm{iii}} * 1
$$

Mean Relevancy Score $(\mathrm{MRS})=$

$$
\text { fx }
$$

$\mathrm{fx}_{\mathrm{i}}=$ Number of more relevant response

$\mathrm{fx}_{\mathrm{ii}}=$ Number of Relevant response

$\mathrm{fx}_{\mathrm{iii}}=$ Number of Least relevant response

$f x=$ Total Number of Judges

With the help of above two criteria the statements having Relevancy Weightage (RW) > 0.70 and Mean Relevancy Score $(\mathrm{MRS})>2.25$ were considered for including in the Awareness Index.

\section{Computation of the composite index}

Each indicator of Awareness Index consists of different number of statement, as result their range of total scores was different. So, total score of each dimension was converted into unit score by using simple range and variance as given below,

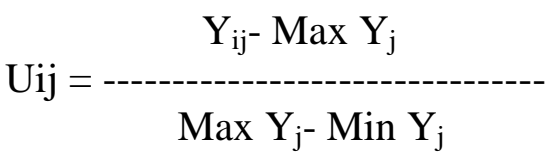

Where,

$U_{i j}=$ Unit score of the ith respondents on $j^{\text {th }}$ dimension

$Y_{i j}=$ Value of the ith respondent on the $j^{\text {th }}$ dimension

Max $Y_{j}=$ Maximum score on the $j^{\text {th }}$ dimension 
Min $Y_{j}=$ Minimum score on the $j^{\text {th }}$ dimension

Awareness Index value for each respondent was obtained by the following formulae:

$$
\mathrm{AI}_{\mathrm{i}}=\frac{\sum \mathrm{U}_{\mathrm{ij}} * \mathrm{~S}_{\mathrm{j}}}{\text { Sum of scale values }}
$$

Where,

$\mathrm{AI}_{\mathrm{i}}=$ Awareness Index of $\mathrm{i}^{\text {th }}$ respondent

$\mathrm{U}_{\mathrm{ij}}=$ Unit score of the $\mathrm{i}^{\text {th }}$ respondent on $\mathrm{j}^{\text {th }}$ component

$S_{j}=$ Scale value of the $j^{\text {th }}$ component

Thus, the score of each dimension range from 0 to 1 i.e. when $Y_{i j}$ is minimum, the score is 0 and when $Y_{\mathrm{ij}}$ is maximum the score is 1 .

\section{Standardization of an index}

Experts' judgment technique was used to test the content validity of the index in which statements with at least 80 percent judges' agreement were retained.

\section{Results and Discussion}

Statements having Relevancy Weightage $(\mathrm{RW})>0.70$ and Mean Relevancy Score (MRS) > 2.25 were considered for including in the Awareness Index.

\section{Purpose of antibiotic prescription}

The antibiotics for therapeutic purpose were given frequently (always) by 95 percent of paravets, while 5 percent of them preferred it less frequently (sometimes). The antibiotic for sub-therapeutic purpose was subjected by 25 percent of the respondents and all of them used it sometimes as indicated in Table 1. Use of antibiotics for prophylactic purpose was practised by 15.00 percent of respondents and all of them prescribed it sometimes.
Table.1 Purpose of antibiotic prescription

\begin{tabular}{|c|l|l|l|l|}
\hline $\begin{array}{l}\text { Sr. } \\
\text { No. }\end{array}$ & Purpose & Always & Sometimes & Never \\
\hline 1 & Therapeutic & 95.00 & 5.00 & 0 \\
\hline 2 & $\begin{array}{l}\text { Sub- } \\
\text { therapeutic }\end{array}$ & 0 & 25.00 & 75.00 \\
\hline 3 & Prophylaxis & 0 & 15.00 & 85.00 \\
\hline
\end{tabular}

Farmer's behavioural aspects affecting antibiotic prescriptions

It is apparent from Table 2 that 40 percent of the farmers asked for a particular drug and mostly it was found to be antibiotics. The interference of farmers based on their previous experience and related disease history was revealed by 25 of the paravets.

It was found that 5 percent of the farmers used to express their concerned knowledge about antibiotics to the paravets (Table 1).

\section{Farmer's behavioural aspects affecting antibiotic prescriptions}

It is apparent from Table 2 that 40 percent of the farmers asked for a particular drug and mostly it was found to be antibiotics. The interference of farmers based on their previous experience and related disease history was revealed by 25 of the paravets. It was found that 5 percent of the farmers used always expressed their knowledge and 15 percent sometimes expressed their knowledge about antibiotics to the paravets (Table 4).

\section{Perceived consequences of irrational prescription of antibiotics}

It was revealed that 15 percent of the respondents were aware about antibiotic resistance and 5 percent were aware about the antibiotic toxicity which was the result of experience based treatment and antibiotic usage based on initial symptom of the disease. 
Table. 2 Selection of indicators for awareness index for paravets

\begin{tabular}{|c|c|c|c|c|c|c|c|c|c|}
\hline \multirow[t]{2}{*}{ ri } & \multirow[t]{2}{*}{$\mathbf{R i}$} & \multicolumn{5}{|c|}{ Indicators for Awareness Index (AI) for paravets } & \multirow[t]{2}{*}{$\sum$} & \multirow[t]{2}{*}{$\mathbf{p}$} & \multirow[t]{2}{*}{$\mathbf{C}$} \\
\hline & & $\begin{array}{c}\text { General } \\
\text { awareness } \\
\text { of issue }\end{array}$ & $\begin{array}{c}\text { Farmer's } \\
\text { behavioural } \\
\text { aspects }\end{array}$ & $\begin{array}{l}\text { Diagnostic } \\
\text { approaches }\end{array}$ & $\begin{array}{c}\text { Animal } \\
\text { husbandry and } \\
\text { management }\end{array}$ & $\begin{array}{l}\text { Animal human } \\
\text { linked } \\
\text { resistance }\end{array}$ & & & \\
\hline 1 & 1 & 7 & 6 & 9 & 3 & 5 & 30 & 90.00 & 8 \\
\hline 2 & 2 & 9 & 6 & 4 & 5 & 6 & 30 & 70.00 & 7 \\
\hline 3 & 3 & 5 & 10 & 7 & 4 & 4 & 30 & 50.00 & 6 \\
\hline 4 & 4 & 6 & 4 & 4 & 10 & 6 & 30 & 30.00 & 6 \\
\hline 5 & 5 & 3 & 4 & 6 & 8 & 9 & 30 & 10.00 & 5 \\
\hline$\sum \mathrm{f}$ & & 30 & 30 & 30 & 30 & 30 & 150 & 250 & 32 \\
\hline$\sum \mathrm{fC}$ & & 200 & 194 & 196 & 183 & 187 & 960 & & \\
\hline $\begin{array}{c}\text { Mc or } \mathrm{Rj} \\
\text { or } \mathrm{Rc}\end{array}$ & & 6.67 & 6.47 & 6.53 & 6.10 & 6.23 & Stand & $\begin{array}{l}4 \sigma=0.2 \\
\text { or for } M\end{array}$ & \\
\hline \multicolumn{10}{|c|}{$\mathbf{r}_{\mathrm{i}}=$ Correct rank order, $\mathbf{R}_{\mathbf{i}}=$ Reverse rank order, $\sum=$ Sum, $\boldsymbol{p}=$ Proportion, $\mathbf{C}=\mathrm{C}$ values of respective ranks, } \\
\hline
\end{tabular}


Table.3 Relevancy and mean relevancy for statement of indicator of awareness index for farmers

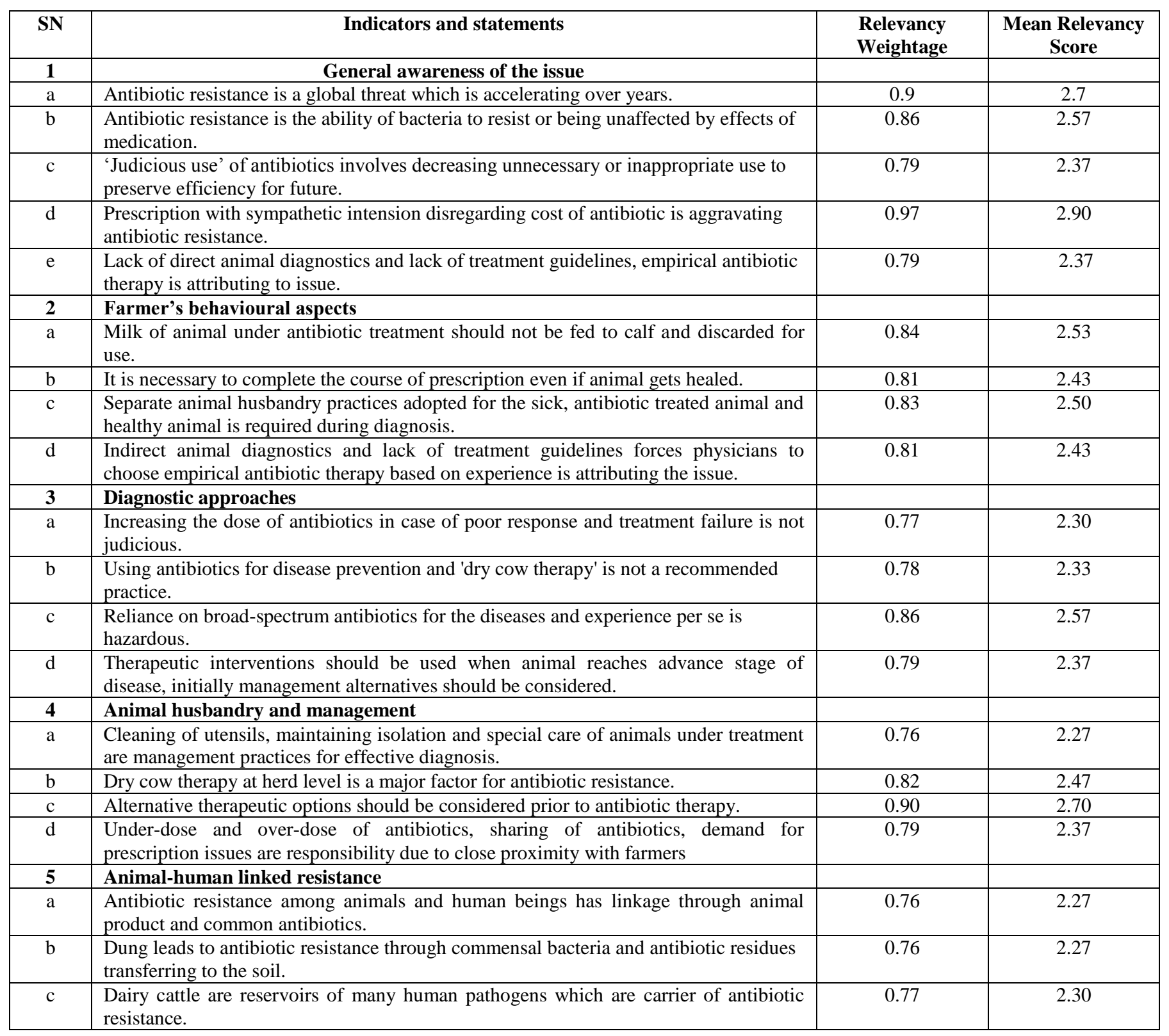

Table.4 Antibiotic prescription and farmer's behavioural aspects

\begin{tabular}{|c|l|c|c|c|}
\hline Sr. No & \multicolumn{1}{|c|}{ Activity showing interest } & Always & Sometimes & Never \\
\hline 1 & They ask for antibiotics & 40 & 15 & 45 \\
\hline 2 & $\begin{array}{l}\text { They discuss the previous experience and related } \\
\text { disease history }\end{array}$ & 5 & 25 & 70 \\
\hline 3 & $\begin{array}{l}\text { They describe the experience of their neighbors/ } \\
\text { relatives/ progressive farmers }\end{array}$ & 5 & 20 & 75 \\
\hline 4 & They express their knowledge about antibiotics & 5 & 15 & 80 \\
\hline
\end{tabular}

(Figures indicate percentage) 
Table.5 Perceived consequences of irrational prescription of antibiotics

\begin{tabular}{|l|l|l|l|}
\hline Sr. No. & Consequences & Agree & Disagree \\
\hline 1. & Antibiotic resistance & 15 & 85 \\
\hline 2. & Antibiotic toxicity & 5 & 95 \\
\hline 3. & Multidrug resistance & 0 & 100 \\
\hline 4. & Increased burden on $3^{\text {rd }}$ and $4^{\text {th }}$ generation antibiotics & 0 & 100 \\
\hline 5. & Increased failure of treatment & 10 & 90 \\
\hline
\end{tabular}

Table.6 Distribution of respondents as per Awareness Index scores about antibiotic resistance

\begin{tabular}{|c|l|c|}
\hline Sr. No. & \multicolumn{1}{|c|}{ Issues } & Awareness Index score \\
\hline 1 & General awareness & 0.14 \\
\hline 2 & Farmer's behavioural aspects & 0.12 \\
\hline 3 & Diagnostic approaches & 0.08 \\
\hline 5 & Animal-human linked transfer of resistance & 0.06 \\
\hline
\end{tabular}

Table.7 Awareness about antibiotic resistance among paravets $(n=25)$

\begin{tabular}{|c|l|c|c|}
\hline Sr. No. & Category & Frequency & Percentage \\
\hline 1 & Low $(<0.09)$ & 11 & 44 \\
\hline 2 & Medium $(0.09-0.19)$ & 8 & 32 \\
\hline 3 & High $(>0.19)$ & 6 & 24 \\
\hline
\end{tabular}

None of the paravets were aware about multidrug resistance and they advised the farmers to visit the veterinary hospital when the two or more antibiotics were found to be ineffective.

None of them were aware about the increased burden on $3^{\text {rd }}$ and $4^{\text {th }}$ generation antibiotics which were common for human and animals. The failure of treatment due to over-use of antibiotics leading to resistance was recognised by 10 percent of the respondents.

\section{Assessment of awareness about antibiotic resistance}

It was done with the help of Awareness Index to identify the practices which should be addressed for controlling the antibiotic resistance in future to build surveillance. The awareness about the issue was judged with respect to diagnostic aspects and practices linked with the disease treatment.
Parameters to assess the awareness level of paraveterinarians regarding antibiotic resistance

\section{General awareness}

Majority of paravets revealed antibiotic resistance as the local threat and were not aware that it had spread throughout the geographical area. They gave antibiotics to farmers for disease treatment and they never focussed on the completing the course of treatment guidelines revealed by score of 0.14 which is apparent in Table 6 .

\section{Farmer's behavioural aspects}

Majority of paravets interrupted their previous treatment course and randomly prescribed the antibiotic based on their experience. They discontinued the treatment as soon as symptoms of disease disappear to save the money of farmers. Table 6 revealed that 
paravets were least aware about the posttreatment follow-up and were having the awareness score of 0.12 in the awareness index. They were least aware about separate animal husbandry practices adopted for the sick, antibiotic treated animals. Lacking awareness about treatment guidelines and technical knowledge about antibiotic resistance phenomena and consequence were responsible were found responsible for low insight in to farmer's behavioural aspects regarding the antibiotic usage practices.

\section{Diagnostic approaches}

Majority of paravets increased the dose of antibiotics in case of poor response and treatment failure. They started the diagnosis with broad-spectrum antibiotics and preferred the clinical and trauma practices on their own risk only when the advance stage of the disease was reached. Majority of paravets never encouraged the alternatives for disease treatment despite their close proximity with farmers and indiscriminately used the antibiotics based on marketing offers and advertisement of new antibiotics. So, due to above reasons they were having very low awareness index score ( 0.08 out of 1.00$)$.

\section{Animal-human linked transfer of resistance}

Paravets were least aware (awareness index score of 0.06 on 1.00 point continuum) that antibiotic resistance could be transferred from cattle to human being via milk and milk products. It was revealed from Table 6 that they were not aware that commensal bacteria in cattle could act as reservoir of antibiotic resistance which get transferred through the dung of cattle and finally incorporated in the food chain.

It is apparent from Table 7 that 44 percent of paravets were having low level of awareness
$(<0.09$ out of 1.00) because they excel in performing artificial insemination services and deworming but in case of bacterial disease treatment they gave common antibiotics and were unaware about its effect other than disease treatment. Medium level of awareness about antibiotic resistance (0.090.19) was found among 32 percent of respondents who were cosmopolite in nature and were active in many surrounding villages. It was found that 24 percent of paravets who were having high awareness $(>0.19$ on 0 to 1 point continuum) about antibiotic resistance were engaged in providing their assisting services to veterinary doctors in veterinary hospitals where antibiotic sensitivity testing laboratory was available. So, they were aware about the resistance because they observed that few progressive farmers used to bring the samples for sensitivity testing. Although, High level of awareness (>0.19) is itself very low, level of awareness when considered as a whole, which is a contrast demands the fullfledge planning from the bottom level to address the issue of antibiotic resistance.

In conclusion, addressing the antibiotic resistance issue through the prevailing practices observed in the study area was a tough task by involving the two stakeholder namely paravets and farmers who were technically unaware about the issue and found incompetent with the prevailing existing practices. The sub-therapeutic use of antibiotics and antibiotic prescription with sympathetic intension, the least awareness about the antibiotic toxicity and no awareness about the multidrug resistance has aggravated the issue leading to a catastrophe. They were generally aware about antibiotic resistance issue and least aware about Animal-human linked transfer of resistance reflected by the awareness index score of 0.14 and 0.06 out of 1.00 which indicates a very low level of awareness. Starting treatment with broadspectrum antibiotics without proper diagnosis 
and simply by observing the symptom and performing the clinical and trauma practices on their own risk were found to be grossly inappropriate approach. Paravets have a better opportunity to interact with farmers through better insight into their behavioural aspects and close supervision of the animal husbandry practices, but they were unable to harness the opportunity due to lack of awareness and technical incompetency. If provided proper training and guidance, they could be better option to fight antibiotic resistance. It is bitter to accept ground- level reality that paravets are performing the diagnosis and treatment mostly in case of smallholder dairy farmers without having awareness and knowledge on antibiotic resistance. Hence there is an urgent need to bring awareness on antibiotic resistance among paravets and formulation of enabling policy as well as an appropriate surveillance program to tackle the issue of antibiotic resistance.

\section{References}

Berglund, B., 2015. Environmental dissemination of antibiotic resistance genes and correlation to anthropogenic contamination with antibiotics. Infection ecology \& epidemiology, 5(1), p.28564.
Borriello, S.P., Price, S., 2013.Factors influencing antibiotic prescribing habits and use of sensitivity testing amongst veterinarians in Europe. Vet. Rec. 173, 475.

Friedman, D.B., Kanwat, C.P., Headrick, M.L., Patterson, N.J., Neely, J.C., Smith, L.U., 2007. Importance of prudent antibiotic use on dairy farms in South Carolina: a pilot project on farmers' knowledge, attitudes and practices. Zoonoses Public Health 54, 366-375.

Gulland, A., 2013. Science ministers discuss the growing threat of antimicrobial resistance. BMJ: British Medical Journal (Online), 346.

Harbarth, S., Balkhy, H.H., Goossens, H., Jarlier, V., Kluytmans, J., Laxminarayan, R., Saam, M., Van Belkum, A. and Pittet, D., 2015. Antimicrobial resistance: one world, one fight! Antimicrobial Resistance and Infection Control, 4(1), p.49.

Schwarz, S., C. Kehrenberg, and T. R. Walsh. 2001. Use of antimicrobial agents in veterinary medicine and food animal production. Int. J. Antimicrob. Agents 17:431-437.

De Briyne, N., Atkinson, J., Pokludova, L.,

\section{How to cite this article:}

Vikash Kumar and Jancy Gupta. 2017. An Analytical Study to Assess the Awareness Level of Para-veterinarians about Antibiotic Resistance in Eastern Haryana, India. Int.J.Curr.Microbiol.App.Sci. 6(10): 1819-1826. doi: https://doi.org/10.20546/ijcmas.2017.610.219 